Original Research Paper

\title{
Surveying for Users' Pattern and Preference of Waterfront Space, Daegu City, South Korea
}

\author{
${ }^{1}$ Ki-Bum Park, ${ }^{2}$ Youngmin Seo, ${ }^{3}$ Seunghyun Kim and ${ }^{4}$ Sungwon Kim \\ ${ }^{1}$ School of Construction Engineering, Kyungil University, Gyeongsan, 38428, South Korea \\ ${ }^{2}$ Department of Constructional Environmental Engineering, Kyungpook National University, Sangju, 37224, South Korea \\ ${ }^{3}$ Daegu International School (DIS), Daegu, 41021, South Korea \\ ${ }^{4}$ Department of Railroad Construction and Safety Engineering, Dongyang University, Yeongju, 36040, South Korea
}

\author{
Article history \\ Received: 27-09-2016 \\ Revised: $15-11-2016$ \\ Accepted: 17-11-2016 \\ Corresponding Author: \\ Sungwon Kim \\ Department of Railroad \\ Construction and Safety \\ Engineering, Dongyang \\ University, Yeongju, 36040, \\ South Korea \\ Email: swkim1968@dyu.ac.kr
}

\begin{abstract}
This research conducts one-to-one survey in respect of the users' state for the Suseong Pond, Sincheon and Palgeocheon, which have different characteristics of Daegu City, South Korea. From the research results, it is found that the Suseong Pond has many facilities to enjoy such as cafe, restaurant, amusement park, small boat etc. The facilities are highly used by young adult group ( 20 and $30 \mathrm{~s}$ ) with well-established trails, sports facilities, etc. The Sincheon is utilized for walking and exercising by the senior group (60s) with festival, educational experience and theme, amusement facilities, etc. The Palgeocheon, which is a waterside space of downtown area, is utilized for walking and exercising by the residents group (40 and 50s), who mostly live within $1 \mathrm{~km}$ from the stream, with amusement facilities, convenience facilities etc. Based on this research, we propose that the characteristics of waterside and its surrounding area should be investigated and considered for the development of waterfront space to reflect users' characteristics and requirements. The development of waterfront space reflecting the characteristics of users, stream, lake and facilities is expected to attract more users and enhance their satisfaction significantly.
\end{abstract}

Keywords: Users' Pattern, Waterfront Space, One-to-One Survey, Daegu City

\section{Introduction}

Recently, as people get abundant time due to economic development, five-day workdays, etc., leisure activity hours have rapidly increased in South Korea. In addition, as urban population is continuously increased and the stability of flood control and water supply is maintained consistently in stream space, demand for water-friendly function in downtown waterfront space has increased significantly. As it is increased, development projects reinforced with water-friendly function have been continuously worked by the Ministry of Land, Infrastructure and Transport (MOLIT), the Ministry of Environment (ME) and local governments, South Korea. As the development projects of urban waterside space are continued, the similar types of water-friendly river projects are controlled. The simple river projects with similar patterns such as trail, exercise facilities, lawn plaza, etc. are implemented. Furthermore, the river projects are accomplished according to the development purposes of national institutes without considering the present condition for local residents and characteristics, users' demands, etc. The utilization of waterside space by local residents is limited mainly to trails, exercise facilities, etc.

In recent years, the previous studies on the development of waterside space have been accomplished by Lee and Lee (2003; Steinwender et al., 2008; Vayona, 2011; Kim and Lee, 2012; Park et al., 2012a; 2012b; 2012c; 2013; 2014; 2015; Faggi et al., 2013; Kang, 2014). Lee and Lee (2003) investigated the utilization of waterside space by apartment residents living near coast, river etc. Steinwender et al. (2008) examined relationship between water quality indices and visitors' waterfront assessments. Vayona (2011) researched individual preferences for waterfront redevelopment and analyzed the relationship between the individual preferences and the waterfront redevelopment using regression analysis. Kim and Lee (2012) performed a survey on safety degree from crime, accessibility, 
convenience and aesthetic impression for the users of three steams such as Seongnaecheon, Yangjaecheon and Cheonggyecheon. Park et al. (2012a) investigated storytelling resources applicable for stream development. Faggi et al. (2013) analyzed preferences for water as a landscape feature using showcasing visitors to waterfronts and residents who live near the waterfronts in urban and suburban areas. Park et al. (2013) studied storytelling methods, which can apply to river development. Kang (2014) investigated the satisfaction and requirements for the uses of trails, bicycle roads and parks provided near streams in provincial cities. Park et al. (2015) examined utilization and preference for urban waterside space.

This study investigates the utilization for waterside spaces, specifically the characteristics of users, streams (Palgeocheon and Sincheon) and pond (Suseong Pond) including their surrounding facilities. Furthermore, this study can attract more users and improve the users' satisfaction reflecting the characteristics for the development of waterside space.

\section{Materials and Methods}

For investigating the utilization of waterside space for urban streams, one-to-one survey was implemented for 467 persons in the Suseong Pond, Sincheon and Palgeocheon, Daegu City, South Korea.

The Suseong Pond is a representative waterside space of Daegu City, where trails, exercise facilities, amusement park, small boat, etc. are provided. Since various events, including firework, image music fountain, etc. are held regularly and there are many restaurants and cafes near the pond, many people visit there on every weekend. The Sincheon, which is a stream flowing through Daegu City, has a good adjacency and provides a space for daily exercise, leisure life and relaxation to citizens. The left and right bank areas of the stream are used as driveway, riverside swimming pool (in summer) and space for various events. The Palgeocheon is an urban stream located in northern residence area of Daegu City, South Korea. The area has developed as the sub-central area of Daegu City recently. Since many resident houses (apartments) are located around the Palgeocheon, many people utilize the streamside space for walking and exercising on the evening time and weekends.

The total population of Daegu City is 2,518,467 and the population of Suseong-gu where the Suseong Pond is located, is 457,976. The areas, which the Sincheon passes through, include Suseong-gu, Jung-gu and Bukgu. The total population of the areas is 986,746. The population of Buk-gu in which the Palgeocheon is located is 449,157 and the population of local residents who mainly utilize the Palgeocheon is 219,202 . Table 1 summarizes the population of Daegu City. Figure 1 shows the study area.
Table 1. Population state of Daegu City

\begin{tabular}{lllll}
\hline & $\begin{array}{l}\text { Number } \\
\text { of house }\end{array}$ & $\begin{array}{l}\text { Population } \\
\text { (persons) }\end{array}$ & (persons) & $\begin{array}{l}\text { Female } \\
\text { (persons) }\end{array}$ \\
\hline Total & 970,618 & $2,518,467$ & $1,255,516$ & $1,262,951$ \\
Jung-gu & 37,220 & 79,610 & 38,806 & 40,804 \\
Dong-gu & 141,918 & 349,619 & 174,188 & 175,431 \\
Seo-gu & 90,413 & 213,136 & 108,027 & 105,109 \\
Nam-gu & 75,028 & 164,483 & 80,118 & 84,365 \\
Buk-gu & 167,760 & 449,157 & 225,051 & 224,106 \\
Suseong-gu & 165,197 & 457,976 & 224,150 & 233,826 \\
Dalseo-gu & 224,083 & 615,140 & 307,375 & 307,765 \\
Dalseong-gun & 68,999 & 189,346 & 97,801 & 91,545 \\
\hline
\end{tabular}

Note. Population data from Daegu City (2015)

The study areas including the Suseong Pond, Sincheon and Palgeocheon, are waterside spaces which are utilized the characteristics of the surrounding areas. The Suseong Pond is located in Suseong-gu, the center of Daegu City. The area of pond is $218,000 \mathrm{~m} 2$ and the total length of trails is about $2,020 \mathrm{~m}$. The Sincheon is an urban stream, which starts from Suseong-gu and combines the tributary of Geumho River. The stream length is $12.4 \mathrm{~km}$ and the stream flows through Suseonggu, Jung-gu and Buk-gu of Daegu City (Ministry of Land, Infrastructure and Transport, 2011). The Palgeocheon, which is an urban stream located in the new town of Buk-gu, Daegu City, is combined the tributary of Geumho River. The total length is $18.14 \mathrm{~km}$ (Ministry of Land, Infrastructure and Transport, 2009).

This study investigated the characteristics of three waterside spaces including the Suseong Pond, Sincheon and Palgeocheon. First, in case of the Suseong Pond located in the downtown of Daegu City, various festivals and events are held in all the times of the year. Music fountain, which is installed in the pond, provides a magnificent show on summer nights. Also, cafes and restaurants are well displayed around the pond, the Suseong Land, which is an amusement facilities, is located around the pond and small boat is operated in the pond. Trails and exercise facilities are installed around the waterside space and the space is utilized for various purposes. Second, the Sincheon is a representative landmark of Daegu City flowing through the city. The Sincheon is an eco-environmentally outstanding space since the stream has wide riverside spaces and otters inhabit the stream. The Sincheon also has long trails and sports facilities. In the Sincheon, various festivals and events are held all the time throughout the year. Since swimming pool and sledding slope are also operated in summer and winter seasons, respectively, many people visit the waterside space. Lastly, the Palgeocheon is a stream flowing through residential area. The Palgeocheon has trails and exercise facilities within $3 \mathrm{~km}$ from the residential area and accessibility to the stream is good. Since the stream is located in the suburban of Daegu City, the waterside space is not crowded and utilized mostly by local residents. 


\section{Results and Discussion}

\section{Results}

\section{Results of Field Survey on Utility of Waterside Space}

This research conducted one-to-one survey for 467 people to investigate the utilization of the Suseong Pond and Sincheon, representative waterside spaces of Daegu City and the Palgeocheon located in the residential zone of suburb, Daegu City.

The survey items are included as the age group, moving distance to reach the waterside space, number of visit, purpose of use, desired contents and facilities. Figure 2-11 summarizes the results for every survey items.

\section{Distribution of Users' Age Group and Gender}

Figure 2 shows the distribution of age group for three waterside spaces including the Suseong Pond, Sincheon and Palgeocheon, respectively. In case of the Suseong Pond, it was observed that the utilization of young adult group (20 and 30s) was high because of many cafes and restaurants and amusement park (Suseong Land). It was observed that the utilization of senior group (60s) was high among the three places. Finally, it was observed that the residents group (40 and 50s) utilized the Palgeocheon frequently.

Figure 3 shows the distribution of gender for three waterside spaces including the Suseong Pond, Sincheon and Palgeocheon, respectively. For the Suseong Pond, the ratio of female was $54 \%$, higher than $46 \%$ of male. For the Sincheon, the ratio of male was $58 \%$, higher than $42 \%$ of female. For the Palgeocheon, the ratio of female was $54 \%$, higher than $46 \%$ of male.

\section{Users' Visiting Frequency, Purpose and Moving Distance}

Figure 4 shows the distribution of visiting frequency for the three waterside spaces including the Suseong Pond, Sincheon and Palgeocheon, respectively. For the Suseong Pond, the visiting were investigated as $36 \%$ (once a week) and $33 \%$ (twice a week), respectively. For the Sincheon, the visiting was investigated as $24 \%$ (once a week), $23 \%$ (twice a week) and $27 \%$ (three times a week), respectively. For the Palgeocheon, the visiting was investigated as $35 \%$ (three times a week), 22\% (twice a week) and 20\% (four times a week), respectively.

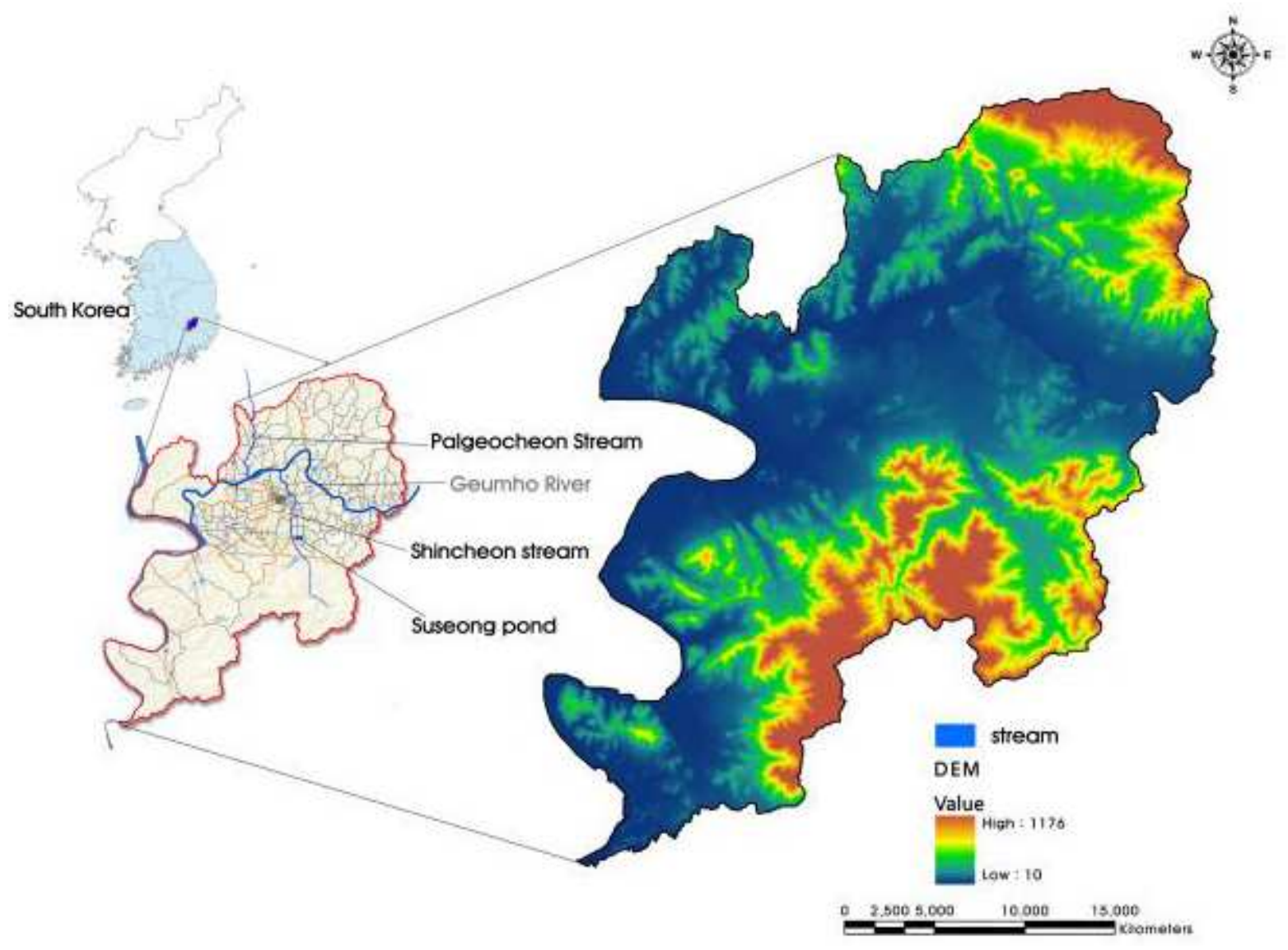

Fig. 1. Study area 


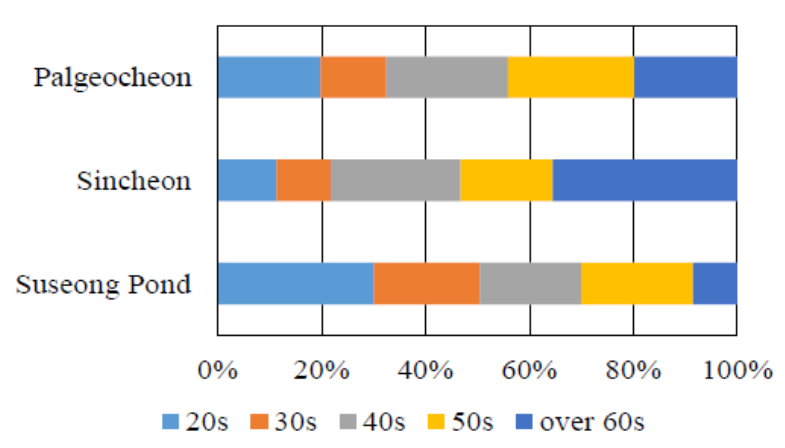

Fig. 2. Distribution of age group

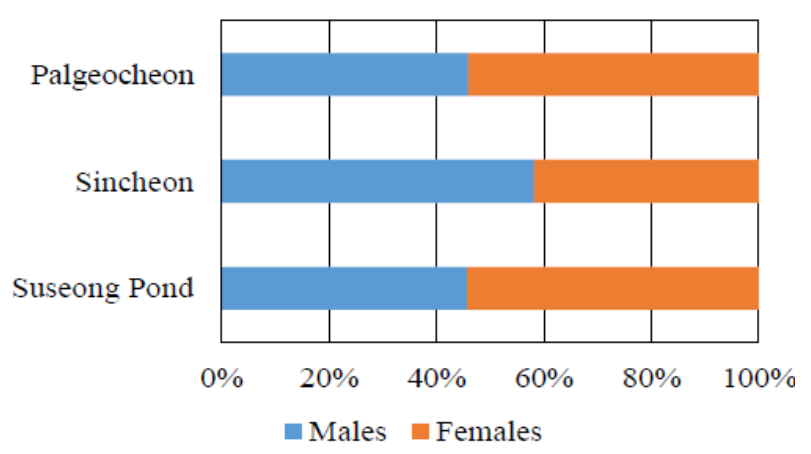

Fig. 3. Distribution of gender

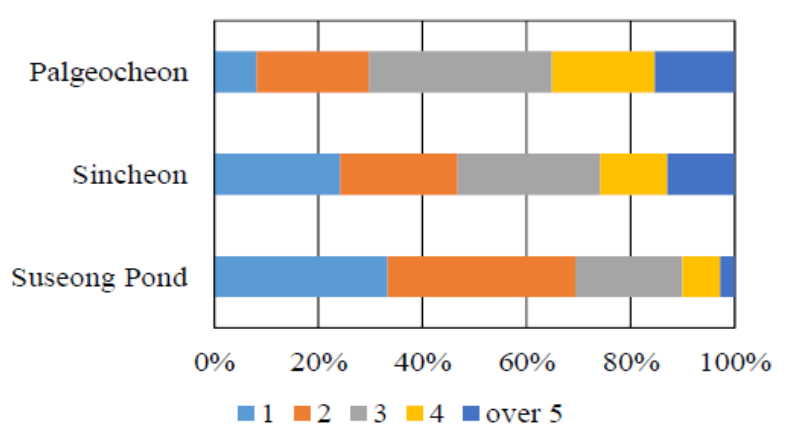

Fig. 4. Distribution of visiting frequency

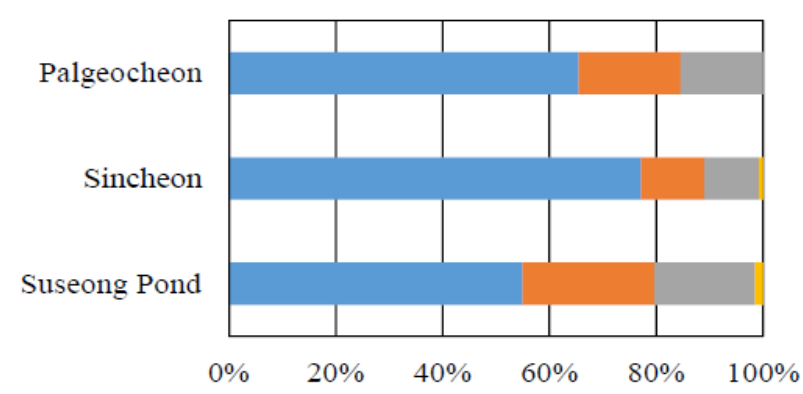

Exercise \& Walking $\square$ Recreation $\square$ Rest $₫$ Education

Fig. 5. Distribution of visiting purposes
Figure 5 shows the distribution of visiting purposes for three waterside spaces including the Suseong Pond, Sincheon and Palgeocheon, respectively. As seen in Fig. 5 , all three places showed the highest ratio for walking and exercising. The Sincheon showed the highest ratio (77\%) among three places for exercise. The Suseong Pond showed the highest ratio (25\%) among three places for recreation, whereas showing the lowest ratio (55\%) among three places for walking and exercising.

Figure 6 shows the distribution of visiting distances for three waterside spaces including the Suseong Pond, Sincheon and Palgeocheon, respectively. As seen in Fig. 6 , for the Suseong Pond, the ratio for visiting distance $(36 \%)$ within $2 \mathrm{~km}$ was the highest among three places. For the Sincheon, the ratio for visiting distances (15\%) over $5 \mathrm{~km}$ were the highest among three places. For the Palgeocheon, the ratio for visiting distance $(52 \%)$ within $1 \mathrm{~km}$ was the highest among three places.

\section{Utilization of Water-Friendly Facilities}

Figure 7 shows the distribution of favorite facilities for three waterside spaces including the Suseong Pond, Sincheon and Palgeocheon, respectively. For the three places, the favorite facilities demonstrated as trails. As seen in Fig. 7, for the Palgeocheon, the ratio for the trails was $69 \%$, which was the highest among the three places. For the Suseong Pond, the ratio for resting area was 23\%, which was over twice times than that of the Palgeocheon.

Figure 8 shows the distribution of favorite spaces for three waterside spaces including the Suseong Pond, Sincheon and Palgeocheon, respectively. Among three places, rest area showed the highest ratio. For the Palgeocheon, ratio for education area reached two times higher than that of the Suseong Pond and Sincheon.

\section{Desired Facilities and Contents for Waterside Space}

Figure 9 shows the distribution of desired themes for three waterside spaces including the Suseong Pond, Sincheon and Palgeocheon, respectively. As seen in Fig. 9, for the three places, the most desiring themes demonstrated as playground. For the Suseong Pond, the ratio for TV program and movie was $33 \%$, which was the highest among the three places. For the Palgeocheon, the ratio for cartoon was $22 \%$, which was the highest among the three places.

Figure 10 shows the distribution of desired facilities for three waterside spaces including the Suseong Pond, Sincheon and Palgeocheon, respectively. As seen in Fig. 10 , for the Suseong Pond, the ratio for rest equipment was $29 \%$, which was the highest among the three places. For the Sincheon, the ratio for exercise equipment was $27 \%$, which was the highest among the three places. For the Palgeocheon, the ratio for amenties was $39 \%$, which was the highest ratio among all three places. 


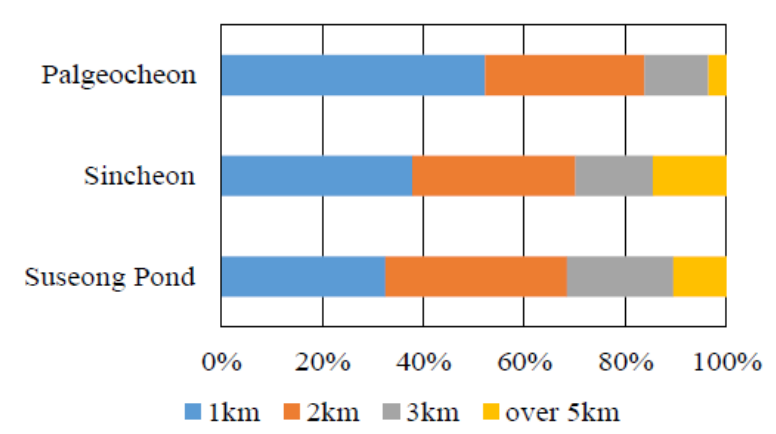

Fig. 6. Distribution of visiting distances

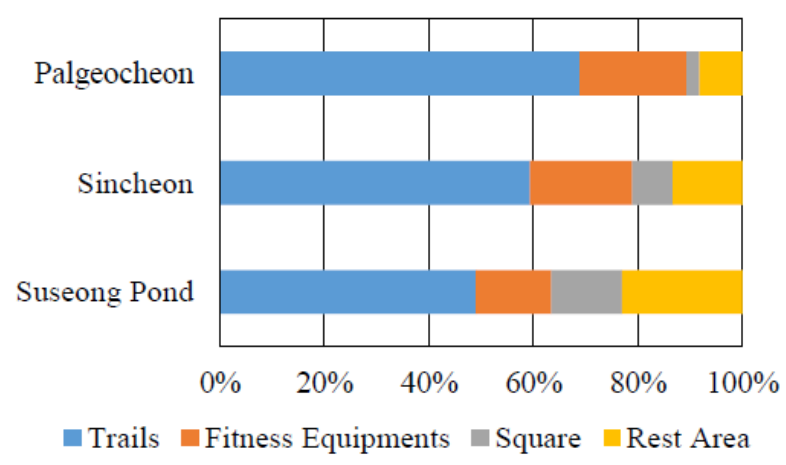

Fig. 7. Distribution of water-friendly facilities

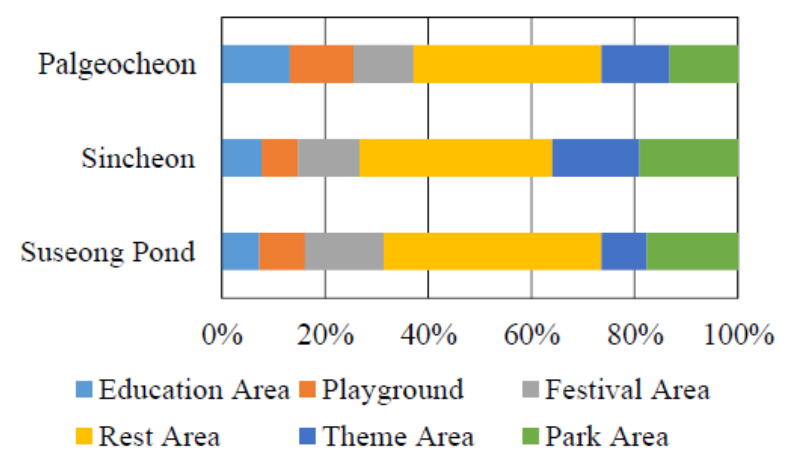

Fig. 8. Distribution of favorite spaces

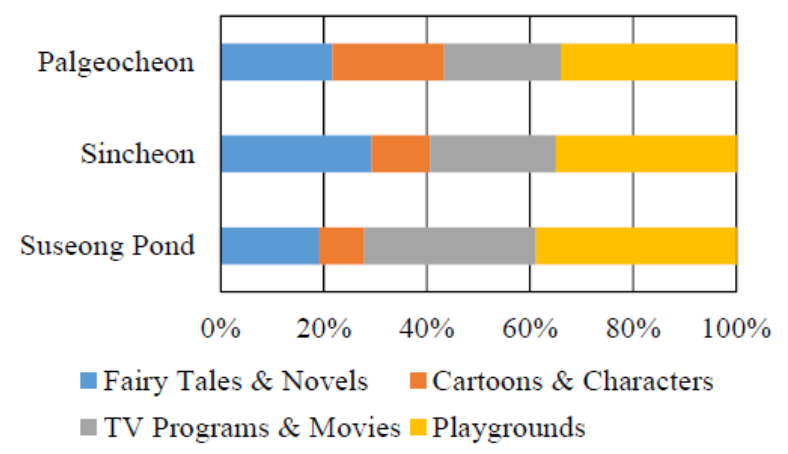

Fig. 9. Distribution of desired themes

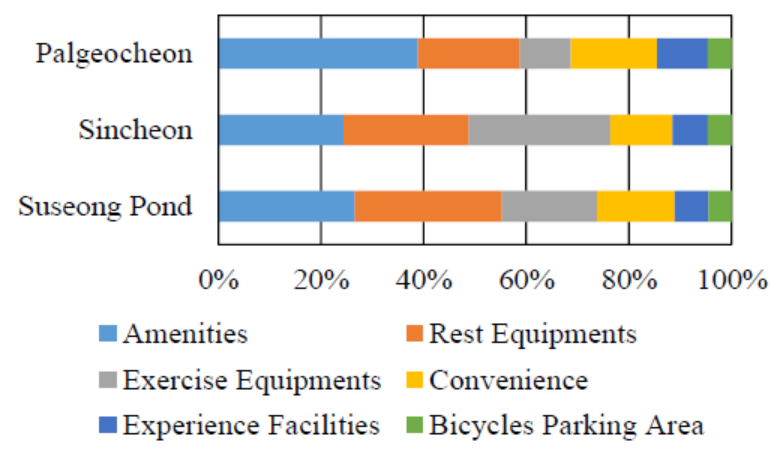

Fig. 10. Distribution of desired facilities

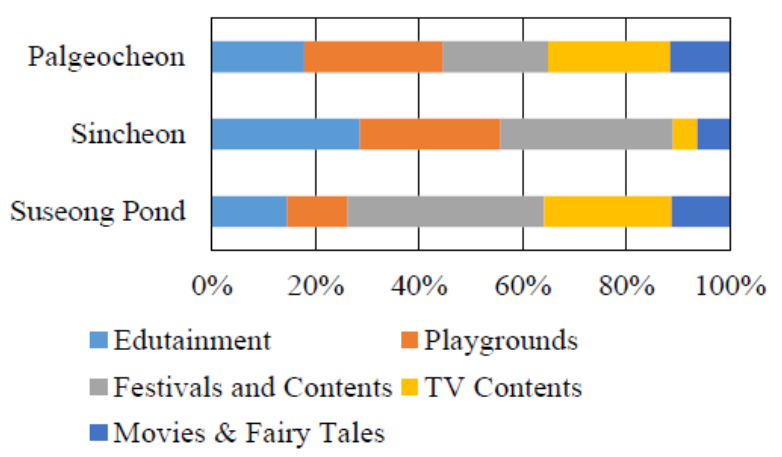

Fig. 11. Distribution of desired contents

Figure 11 shows the distribution of favorite contents for three waterside spaces including the Suseong Pond, Sincheon and Palgeocheon, respectively. As seen in Fig. 11, For the Suseong Pond, the ratio for festival and contents was $38 \%$, which was the highest among the three places. For the Sincheon, the ratio for edutainment was $29 \%$, which was the highest among three places. For the Palgeocheon, the ratio for playground was $27 \%$, which was the highest among three places.

\section{Discussions}

This research surveyed the utilization pattern for three waterside spaces including the Palgeocheon, Sincheon and Suseong Pond. As the results, for the Suseong Pond, it was used for walking and exercising by the female who were in their 20s'. The residents, who lives within $2 \mathrm{~km}$ from the Suseong pond, utilized its trails frequently (once a week) for walking and exercising and visited the Suseong pond for resting. They desired additional exercise equipment, rest equipment, festival and contents. For the Sincheon, the residents (men over 60s), who lives within $1 \mathrm{~km}$ from the Sincheon, utilized its trails frequently (three times a week) for walking and exercising and visited the Sincheon for resting. They desired additional exercise equipment, rest equipment, festival and contents. For the Palgeocheon, the residents (females over 50s), who lives 
within $1 \mathrm{~km}$ from the Palgeocheon, utilized its trails frequently (three times a week) for walking and exercising and visited the Palgeocheon for resting. They desired additional exercise equipment and convenience.

\section{Table 2. Characteristics and use pattern for the Suseong Pond}

Location map

Characteristics of facilities

Surrounding characteristics

Use pattern

Requirements

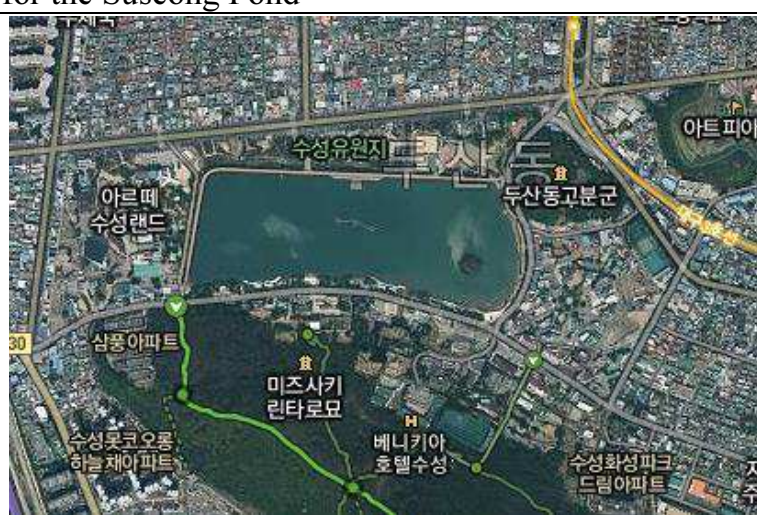

Lake, trails, exercise facilities, music fountain and small boat

Cafes, restaurants, large apartments and central area of urban downtown

20 s, female, twice times a week, exercise, walking, within $2 \mathrm{~km}$ and preference for rest space Play theme, rest facilities and festival

Note. Location map from Daum Map (http://map.daum.net)

Table 3. Characteristics and use pattern for the Sincheon

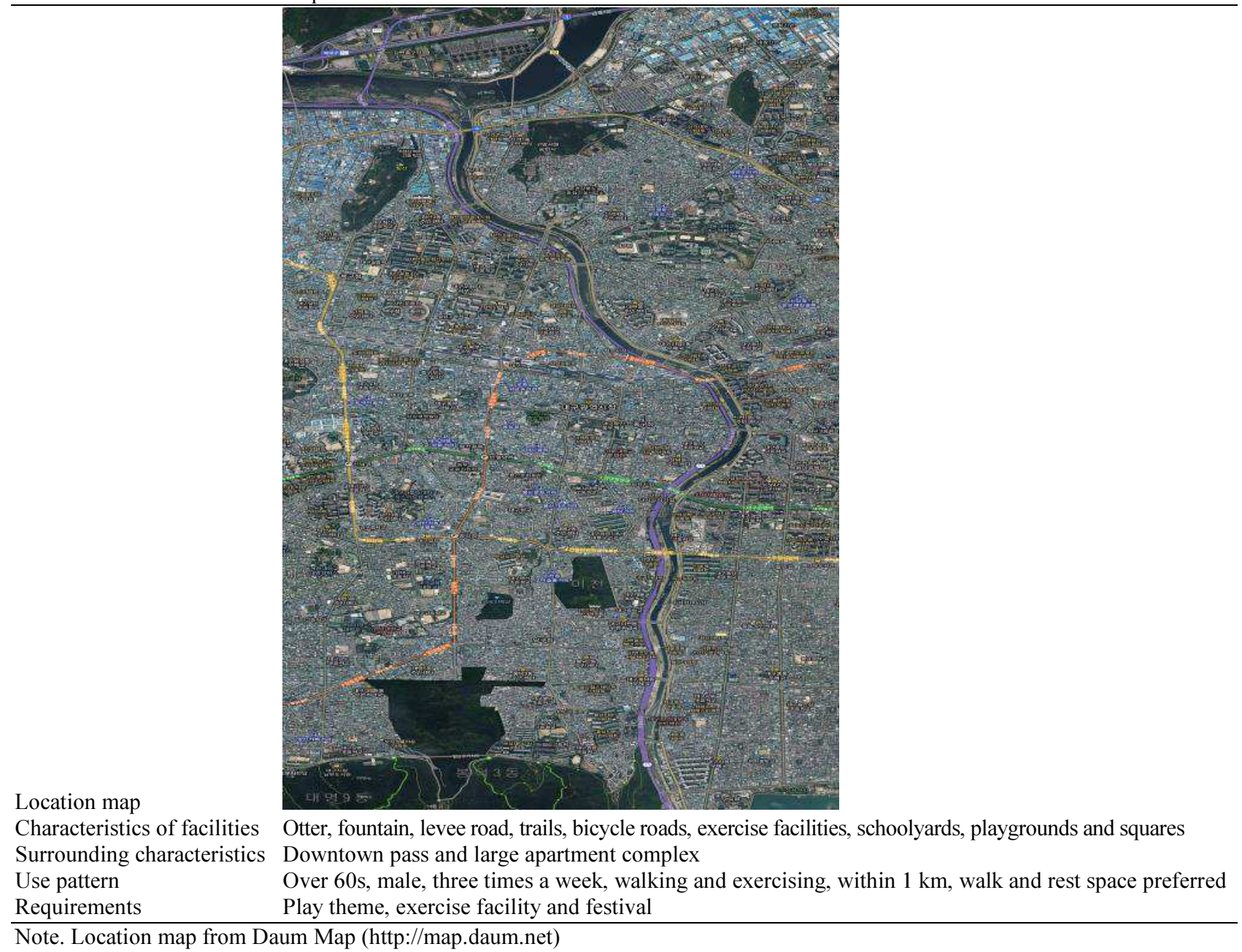

Note. Location map from Daum Map (http://map.daum.net) 
Table 4. Characteristics and use pattern for the Palgeocheon

Location map

Characteristics of facilities

Surrounding characteristics

Use pattern

Requirements

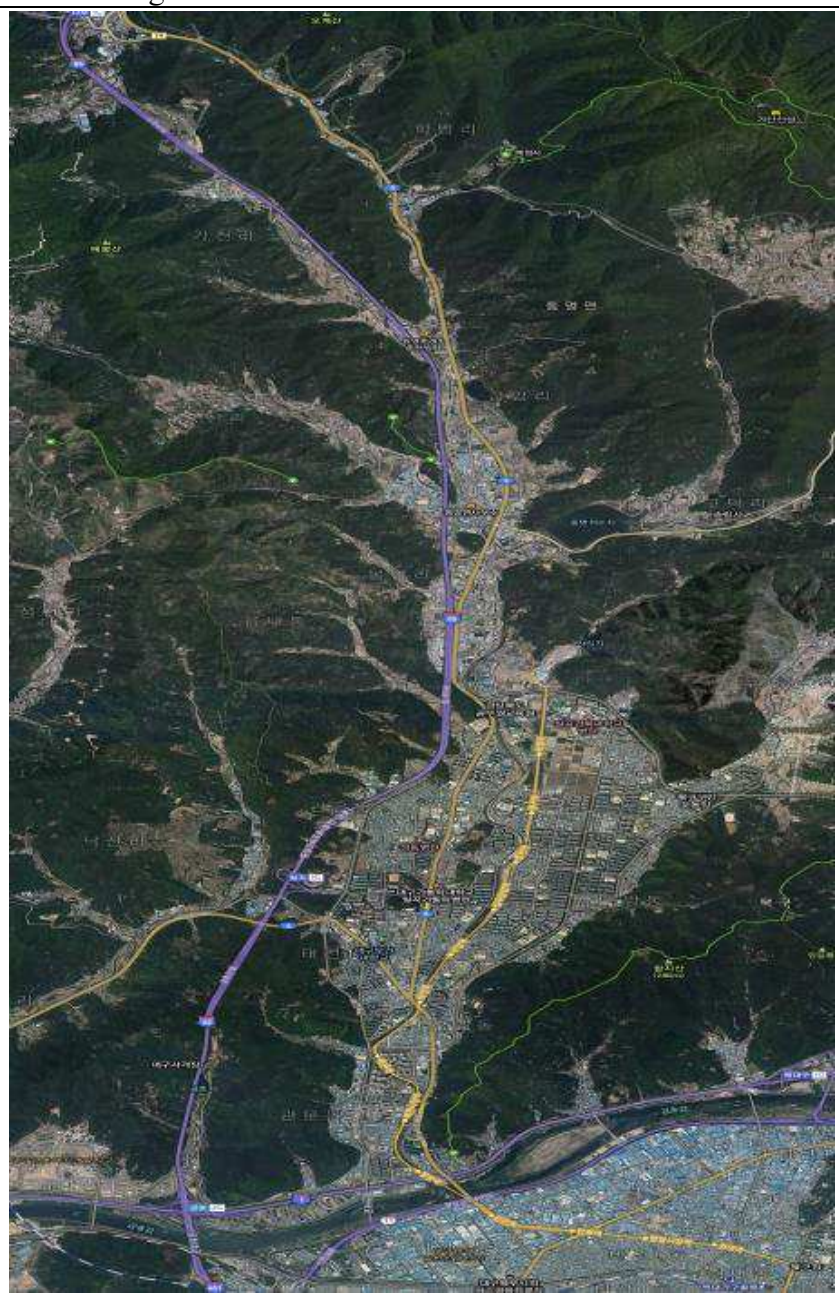

Trail, bicycle road, exercise facility, schoolyard and road

Nearby residence area, quiet and not complex

$50 \mathrm{~s}$, female, three times a week, walking and exercising, within $1 \mathrm{~km}$, trails and rest space use Play theme, amusement facilities and schoolyard

Note. Location map from Daum Map (http://map.daum.net)

Table 2-4 summarizes the characteristics and users' pattern for three waterside spaces including the Palgeocheon, Sincheon and Suseong Pond. For the Suseong Pond, the people, who live over $3 \mathrm{~km}$ from the Suseong pond, visited there. The users desired additional exercise equipment, rest equipment, festival and contents. Therefore, it is necessary to develop cultural spaces for various festivals and contents.

For the Sincheon, the ration for walking and exercising was $77 \%$, which was the highest among the three places. The ratio for fairy tales and novels was also high. The users desired additional exercise equipment, rest equipment, festival and contents. Therefore, it is necessary to arrange facilities and spaces, based on various themes and educational contents. For the Palgeocheon, the users, who live within $1 \mathrm{~km}$ from the Palgeocheon, utilized the exercise facilities (52\%) and trails $(69 \%)$. The ratio for edutainment was relatively high (13\%). As the results, local residents used a waterside space in the Palgeocheon. The age group and composition of local residents affected the use pattern. Therefore, for the Palgeocheon, it is necessary to arrange additional facilities for education and children since the development projects around the Palgeocheon's area is scheduled for the new town.

\section{Conclusion}

This research investigates users' state, pattern and demands for developing effective utilization measures of waterside spaces. This research analyzes users' pattern based on one-to-one survey for the residents who utilize three waterside spaces, including the Suseong Pond, Sincheon and Palgeocheon which are the representative 
waterside spaces of Daegu City. As a result, the Suseong Pond is found to be a space in which the users use cafes and restaurants and enjoy various event festivals, ordinary exercise and walk. It is also found that the users including Daegu citizen visit the Suseong pond from a distance. For the Sincheon, it is found that the waterside space to which the users can approach is widely distributed since the stream flows through Daegu City. It is also found that the users can enjoy various events, exercise and walk. For the Palgeocheon located in residential area, it is found that the stream is a waterside space mostly utilized by the local residents and its approach distance and time is short, compared with other waterside spaces. These results indicate that users' demands vary depending on the location of waterside space, the users' age distribution, etc. Furthermore, it is found that the Suseong Pond requires facilities and contents for rest, exercise and festival, the Sincheon for walking, exercise and various themes and the Palgeocheon for walking, exercising and facilities for all family group. It is expected that this research can improve the development of waterside spaces and raise users' satisfaction by investigating and reflecting users' pattern and urban characteristics for the surrounding area.

\section{Acknowledgement}

\section{Author's Contribution}

Ki-Bum Park: Contributed to conceptualization, survey and manuscript preparation.

Youngmin Seo: Contributed to interpretation, figures and manuscript revision.

Seunghyun Kim: Contributed to English proofreading and editing.

Sungwon Kim: Contributed to manuscript review, revision and research supervision.

\section{Ethics}

The authors confirm that this work is original and has not been published elsewhere.

\section{References}

Daegu, 2015. Daegu statistical yearbook. Daegu.

Faggi, A., J. Breuste, N. Madanes, C. Gropper and P. Perelman, 2013. Water as an appreciated feature in the landscape: A comparison of residents' and visitors' preferences in Buenos Aires. J. Clean. Prod., 60: 182-187. DOI: $10.1016 /$ j.jclepro.2011.09.009

Kang, S.J., 2014. A study of analysis of present condition and users' behavior waterfront in local city-Focusing on Nam river, Taewha river, Gumho river. J. Korean Ins. Rural Archit., 16: 53-61.

DOI: 10.14577/kirua.2014.16.1.53
Kim, H.J. and K.H. Lee, 2012. Analysis of factors affecting satisfaction for using the pedestrian space of the river in Seoul-Focusing on Seongnaecheon, Yangjaecheon, Cheonggyecheon. J. Archit. Ins. Korea, 28: 143-150.

Lee, Y.H. and H.J. Lee, 2003. A study on the residents' using behavior of the waterside in the waterfront apartment Complex. J. Archit. Ins. Korea, 19: 31-38.

Ministry of Land, Infrastructure and Transport, 2009. Basic Plan for Palgeocheon (Amendment). Ministry of Land, Infrastructure and Transport, pp: 1-1.

Ministry of Land, Infrastructure and Transport, 2011. Basic Plan for Sincheon (Amendment). Ministry of Land, Infrastructure and Transport, pp. 2-4.

Park, K.B., H.J. Lee and O.J. Kwon, 2012a. A study on resources applicable for waterfront areas. Proceedings of the Korean Water Resources Association, (WRA' 12), Jungsun Gun, South Korea, pp: 755-758.

Park, K.B., S.S. Ahn, M.J. Kim and S.Y. Park, 2015. A study on a preference survey in constructing waterfront area storytelling. Proceedings of the Korean Environment Science, (KES' 12), Chungju, South Korea, pp: 491-495.

Park, K.B., S.Y. Park and H.J. Lee, 2012b. Storytelling techniques about the application of fairy tales and games for waterfront areas. Proceedings of the Korean Water Resources Association, (WRA' 12), Jungsun Gun, Korea, pp: 761-764.

Park, K.B., S.Y. Park and S.W. Kim, 2012c. Applicability of waterfront area storytelling in applying edutainment. Proceedings of the Korean Water Resources Association, (WRA' 12), JungsunGun, South Korea, pp: 751-754.

Park, K.B., S.Y. Park, H.J. Lee and K.S. Lim, 2013. A study on storytelling techniques applicable in waterfront development. Proceedings of the Korean Environment Science, (KES' 12), Kangreung, South Korea, pp: 491-495.

Park, K.B., S.Y. Park, Y.M. Seo and S.H. Cha, 2014. A study on storytelling contents for constructing waterfront area. Proceedings of the Korean Environment Science, (KES' 12), Busan, South Korea, pp: 610-614.

Steinwender, A., C. Gundacker and K.J. Wittmann, 2008. Objective versus subjective assessments of environmental quality of standing and running waters in a large city. Landscape Urban Plan., 84: 116-126. DOI: 10.1016/j.landurbplan.2007.07.001

Vayona, A., 2011. Investigating the preferences of individuals in redeveloping waterfronts: The case of the port of Thessaloniki-Greece. Cities, 28: 424-432. DOI: 10.1016/j.cities.2011.05.007 